\title{
Converging Evidences on the Eventivity of Italian Nouns
}

\author{
Irene Russo \& Tommaso Caselli
}

\begin{abstract}
This paper aims at shedding lights on the semantic concept of "event noun". Starting with the working hypothesis that linguistic context and corpus-based distributional information can be decisive, we propose a measure for eventivity that relies on syntagmatic cues. By means of a comparison between speakers' judgments and syntagmatic evidence obtained from a corpus study, we propose a measure of eventivity for nouns. The comparison with annotated data proves its soundness.
\end{abstract}

\section{Introduction}

Defining what is an event noun is not an easy task: this notion is widely based on deverbal nouns as morphologically marked items, but some deverbal nouns are not purely eventive and other event nouns are not morphologically derived, i. e. do not have a corresponding verb. Most previous research (Grimshaw 1990, Zucchi 1993, Alexadiou 2001, Alexadiou \& Grimshaw 2008 among others) on the status of event nouns and methods for their identification has mainly concentrated on nominalizations (i. e. the morphological process of creating a noun from a verb), but providing this kind of definition for an event noun cannot assure a well balanced semantic description of this concept.

Following Firth's 1957 intuition that "[y]ou shall know a word by the company it keeps" (Firth 1957:11), the relevance of linguistic context and corpus-based distributional information for the definition of word semantic representations is widely acknowledged (Hovy 2010, Basili \& Pennacchiotti 2010, McDonald \& Schillcock 2001 among others). The idea that co-occurrence statistics of words 
extracted from text corpora can provide a basis for semantic representations has been investigated in Computational Linguistics (see the distributional semantic models proposed by Baroni \& Lenci 2010) but it is useful also from a theoretical point of view (Lenci 2008).

In this work we support the hypothesis that the notion of event noun is a scalar concept which can be modulated along a continuum of eventivity (see also Simone 2008). The identification of event readings for nouns is accomplished in the linguistic context, i. e. by exploiting selectional preferences in terms of verbs and adjectives which co-occur with the noun. The focus of our work is on the factors that can potentially determine the emergence of a noun as eventive apart from morphological marking. We propose a measure for eventivity that relies on syntagmatic cues. The comparison between syntagmatic evidence and speakers' judgments will provide useful insights for event nouns that are not deverbal.

A measure of eventivity can be useful for practical implementations such as automatic event detection for information extraction and question-answering systems but it is also promising for theoretical linguistics because it is not sufficient to say that words display along a continuum, but it is necessary to find out how to represent this continuum and how to enrich it. Moreover, we believe that a measure for eventivity could be useful for detection of coercions as well.

In Section 2, we clarify the theoretical background of our analysis, without forgetting to highlight limitations and difficulties that arose in our work. Data gathered form corpora will support our assertions, paving the way for more detailed corpus analysis.

In Section 3, we describe the preliminary corpus analysis that has been useful to define our working hypothesis. First, we present the corpus-based measure of eventivity and, then, we evaluate its relationship with respect to other kind of information (speakers' judgements). Finally, we wrap up with conclusions and some suggestions for future research.

\section{Decisive variables for the identification of event nouns}

We started this analysis wondering what are the crucial factors which may help in identifying nouns that denote events. The first, most plausible variable pertains to morphological suffixation. In Italian, as well in other languages, nouns can 
be derived by verbs and different suffixes can apply to this derivation process. However, only a subset of them allows the derivation of eventive nouns.

Morphological derivation is only one of the factors which contribute to the individuation of an event noun because it is possible that a deverbal noun codifies more than one meaning and just one of these is eventive. As Bisetto \& Melloni (2007) note, deverbal nominals, such as "traduzione" [translation], are semantically ambiguous since they can refer either to the action/event expressed by the base verb or to its result, i. e. the outcome of the action:

(1) La traduzione di questo testo è lenta e faticosa. [EVENT]

[The translation of this text is slow and difficult.]

(2) Molte traduzioni sono piene di errori. [RESULT]

[Many translations are full of mistakes.]

Moreover, according to the authors, nominals can also have a concrete result interpretation through metonymic transposition, for instance, when they denote the (physical) object which contains the translation:

\section{La traduzione è sul tavolo. [PHYS_OBJ]}

[The translation is on the table.]

The well-known polysemous alternation between an event and a result reading of a deverbal noun (Grimshaw 1990) poses a first, interesting constraint on the relationship between deverbal nouns and event nouns.

As a starting point to investigate this issue, we chose the first 12 most frequent deverbal nouns with suffixes - mento, -aggio, -tura, -zione in the corpus La Repubblica (Baroni et al. 2004). A detailed analysis of the senses of these nouns (Table 1) encoded in a lexicographic dictionary - the De Mauro-Paravia dictionary (De Mauro 2004) - has shown that among these deverbal nouns only $40 \%$ encode only the eventive reading. On the other hand, in the vast majority of the cases, there is an eventive and a result reading or, even, idiosyncratic meanings that are not related to the meaning of the verb, i. e. which do not correspond to the classic pattern meaning of deverbal nouns "the act/process of $-V$ ".

A preliminary research question we address in this paper is: if morphological suffixes will not be sufficient variables for event nouns identification, how to find these items in a corpus? 
Table 1: Number of morphologically derived nouns with a non-eventive sense

\begin{tabular}{|l|l|l|}
\hline Suffix & nouns & non_eventive \\
\hline -zione & 12 & 9 \\
\hline -mento & 12 & 10 \\
\hline -tura & 12 & 8 \\
\hline -aggio & 12 & 2 \\
\hline & 48 & 29 \\
\hline
\end{tabular}

Since Grimshaw's characterization of nominalizations, syntagmatic co-occurrences emerge as cues to disambiguate between an eventive and a non-eventive reading of the same noun. As Zucchi (1993) points out "[t]he of-phrase and the $b y$ phrase occurring in event-denoting NPs are arguments of the nouns with which they combine." (Zucchi 1993:135).

(4) La costruzione (del palazzo) è durata due anni. [EVENT]

[The building (of the house) took two years.]

(5) La costruzione ( ${ }^{*}$ del palazzo) è alta due piani. [RESULT]

[The building ( ${ }^{*}$ of the house) is two floors high.]

Unfortunately, such information is not explicitly available in corpora. To overcome this shortcoming, we considered as relevant cues for the identification of event readings of deverbal nouns other syntagmatic cues. To accomplish this task, the following quote by Vendler (1967: 141) suggested a promising direction:

"There are certain nouns that are not verb derivatives, yet behave like nominalised verbs; that is, they can enter container contexts without suggesting suppressed nominals. Fires and blizzards, unlike tables, crystals, or cows, can occur, begin, and end, can be sudden or prolonged, can be watched and observed - they are, in a word, events and not objects." (Vendler 1967:141).

If events are basically things that happen, event nouns denote things that happen, that occur, that begin, that can be prolonged. Such an approach is not innovative per se, because according to linguists co-occurrences with some verbs (e. g. to attend) can be used as a diagnostic for eventivity even when nouns are not morphologically derived:

(6) I rarely attend beer festivals. (BNC) ${ }^{1}$

1 Examples (7) and (8) are extracted from the British National Corpus (BNC), available at http:// www.natcorp.ox.ac.uk/ 
(7) He wished to attend a workshop in Hawaii. (BNC)

Even among non-deverbal nouns, issues linked to polysemy and alternate readings between eventive and non-eventive readings are present and the role of the co-textual elements with which they co-occur is pivotal to disambiguate and identify the correct reading, as illustrated in examples (8) and (9) below:

(8) L'assemblea ci sarà il 20 Marzo. [EVENT]

The meeting will be on March, $20^{\text {th }}$

(9) L'assemblea ha deliberato l'approvazione del bilancio. [HUMAN_GROUP] The board/assembly has approved the budget proposal.

In (8), the noun "assemblea" [meeting] acquires an eventive reading due to the presence both of the verb "to be" and of the temporal expression which locates the event on the time line, while in (9), the verb "deliberare" [to approve] has a semantic preference for the ontological type of "human/human group" in the subject position which is realized by the noun "assemblea" [assembly/board]. Notice that these two cases are not to be confused with cases of type coercion of the noun "assemblea", but they are due to the intrinsic polysemy of this noun ${ }^{2}$.

Previous semantic analyses (Gross \& Kiefer 1995) exploited a limited set of tests based on the occurrences with peculiar verbs, such as phasal or aspectual predicates like "to begin", "to conclude", adjectives (10a), modification by temporal adverbs (10b) or temporal prepositions (10c). However, we believe these tests are not fully satisfying because they don't asses the ultimate import of all these syntagmatic cues in determining to what extent a noun denote an event, i. e. its degree of eventivity.

(a) The frequent trips were a nuisance.

(b) The destruction of the city in only two days appalled every one.

(c) During the party, John left.

One intuitive way to deal with this problem - the imperfect matching between deverbal nouns and event nouns - is to characterize contextually an event noun, discovering salient syntagmatic cues.

2 Notice that the English translations of the Italian noun "assemblea" are two different nouns, namely "meeting" for the eventive sense and "assembly" for the human group 
It is promising to operationalize classical diagnostic tests in corpus analysis by providing representations with prototypical and less prototypical elements that sound at least more objective than representations based only on intuitions. Distributed and contextually derived representations obtained by syntagmatic evidence are useful to make automatic identification of semantically similar words and categorical distinctions among semantic classes (Lin 1998, Boleda et al. 2004).

As a consequence, summing the frequencies in several syntagmatic contexts could potentially guarantee a better understanding of the concept of event noun. On the basis of an extended corpus analysis we have identified a preliminary list of verbal and adjectival cues of eventivity for Italian nouns (see Section 3 for a detailed description of the methodology used). Here, we report the data relative to nouns not morphologically derived that most frequently co-occur in the corpus La Repubblica with the verbs "continuare" [to continue], "cominciare" [to begin] and with the adjectives "precedente" [previous] and "successivo" [following] (see Table 2 below). They are - at least partially in several cases - nouns that denote events but are not morphologically derived by verbs, such as "guerra" [war], "campionato" [championship], "crisi" [crisis].

If we compare their co-occurrence frequencies divided by the overall corpus frequency with those of the most frequent deverbal nouns, it clearly emerges that not morphologically derived nouns frequently co-occuring with "cominciare" and "successivo" can be as eventive as deverbal nouns (see Table 3 and Table 4).

Table 2: Most frequent nouns that co-occur with relevant syntagmatic cues.

\begin{tabular}{|l|l|l|l|l|l|}
\hline Noun & frequency & cominciare & continuare & precedente & successivo \\
\hline guerra & 133072 & 202 & 246 & 34 & 19 \\
\hline trattativa & 51517 & 172 & 189 & 27 & 25 \\
\hline campagna & 56937 & 166 & 62 & 40 & 11 \\
\hline partita & 89172 & 145 & 15 & 88 & 51 \\
\hline campionato & 36762 & 116 & 11 & 28 & 25 \\
\hline avventura & 19428 & 101 & 35 & 14 & 11 \\
\hline attività & 84840 & 62 & 112 & 49 & 16 \\
\hline riunione & 52559 & 55 & 17 & 105 & 112 \\
\hline colloquio & 28830 & 48 & 36 & 17 & 36 \\
\hline crisi & 107664 & 60 & 33 & 56 & 39 \\
\hline battaglia & 49687 & 125 & 194 & 4 & 7 \\
\hline offensiva & 10215 & 21 & 60 & 0 & 5 \\
\hline
\end{tabular}


Converging Evidences on the Eventivity of Italian Nouns

Table 3: Normalized frequencies of nouns with the verb "cominciare" [to begin/to start].

\begin{tabular}{|l|l|l|l|}
\hline $\begin{array}{l}\text { Non - deverbal } \\
\text { nouns }\end{array}$ & $\begin{array}{l}\text { Normalized } \\
\text { Frequency }\end{array}$ & $\begin{array}{l}\text { Deverbal } \\
\text { nouns }\end{array}$ & $\begin{array}{l}\text { Normalized } \\
\text { Frequency }\end{array}$ \\
\hline avventura & .519 & pestaggio & .410 \\
\hline trattativa & .333 & montaggio & .170 \\
\hline campionato & .315 & monitoraggio & .146 \\
\hline campagna & .291 & operazione & .137 \\
\hline battaglia & .251 & riciclaggio & .105 \\
\hline offensiva & .205 & marcatura & .094 \\
\hline colloquio & .166 & boicottaggio & .093 \\
\hline partita & .162 & lettura & .092 \\
\hline guerra & .151 & trasferimento & .091 \\
\hline riunione & .104 & manifestazione & .070 \\
\hline attività & .073 & risanamento & .059 \\
\hline crisi & .055 & sabotaggio & .057 \\
\hline
\end{tabular}

Table 4: Normalized frequencies of nouns with the adjective "successivo" [following].

\begin{tabular}{|l|l|l|l|}
\hline $\begin{array}{l}\text { Non - deverbal } \\
\text { nouns }\end{array}$ & $\begin{array}{l}\text { Normalized } \\
\text { Frequency }\end{array}$ & $\begin{array}{l}\text { Deverbal } \\
\text { nouns }\end{array}$ & $\begin{array}{l}\text { Normalized } \\
\text { Frequency }\end{array}$ \\
\hline riunione & .213 & passaggio & .334 \\
\hline colloquio & .124 & pestaggio & .082 \\
\hline campionato & .068 & riapertura & .062 \\
\hline partita & .057 & dichiarazione & .054 \\
\hline avventura & .056 & monitoraggio & .048 \\
\hline offensiva & .048 & montaggio & .048 \\
\hline trattativa & .048 & elezione & .047 \\
\hline crisi & .036 & pagamento & .026 \\
\hline campagna & .019 & sondaggio & .019 \\
\hline attività & .018 & movimento & .019 \\
\hline guerra & .014 & fallimento & .018 \\
\hline battaglia & .014 & fornitura & .016 \\
\hline
\end{tabular}

\subsection{A caveat on polysemy}

The graded representation available for event nouns, i. e. the existence of a continuum of eventivity, is mainly due to polysemic alternations: a single word is less perceived as an event by a speaker and displays a lower eventivity value if it has also another sense - for instance a result reading - available.

The degree of eventivity for a deverbal noun could intuitively depend on the number of non-eventive senses codified. For instance, if we consider the senses 
encoded into a lexical resource like ItalWordNet (IWN), we could state that the lexeme "sabotaggio" [sabotage] is more eventive than "formazione" [training]: the former has 3 senses/readings encoded into the resource and all of them denote an event, while the latter has 6 senses/readings encoded and only 3 of them are eventive.

However, for polysemous nouns it is not so automatic to establish a ranking because a sense could be more salient than the others. Looking at the normalized frequencies of co-occurrences with relevant syntagmatic cues (from column "cominciare" to "sum" in Table 5 below) could be useful because they provide a graded representation in place of the static representation of the lexicographic resources (columns "\# of senses”, "eventive senses" Table 5 below).

Unsurprisingly, syntagmatic cues select as more eventive nouns that codify just eventive sense(s), such as "pestaggio" [beating], "manifestazione" [manifestation], "risanamento" [recovery]. On the other hand, the salience on the eventive reading for polysemous nouns is signalled by the frequent co-occurrences with "continuare" [to continue], "cominciare" [to begin/to start] and similar, even when the nouns have just one eventive sense while the others are not eventive, such as for "dichiarazione" [declaration] and "lettura" [reading].

Table 5: Eventive readings from IWN vs. occurrences with relevant syntagmatic cues ("continuare" [to continue], "cominciare" [to begin/to start], "precedente" [preceeding] and "successivo" [following])

\begin{tabular}{|l|l|l|l|l|l|l|l|}
\hline noun & $\begin{array}{l}\text { \# of } \\
\text { senses }\end{array}$ & $\begin{array}{l}\text { eventive } \\
\text { senses }\end{array}$ & comiciare & continuare & precedente & successivo & sum \\
\hline pestaggio & 1 & 1 & .410 & .493 & .0 & .082 & .986 \\
\hline dichiarazione & 3 & 1 & .021 & .029 & .250 & .054 & .359 \\
\hline operazione & 3 & 3 & .137 & .056 & .101 & .015 & .311 \\
\hline sondaggio & 1 & 1 & .014 & .009 & .242 & .019 & .285 \\
\hline montaggio & 2 & 2 & .170 & .0 & .024 & .048 & .243 \\
\hline manifestazione & 4 & 4 & .070 & .099 & .041 & .010 & .223 \\
\hline amministrazione & 3 & 1 & .005 & .001 & .199 & .001 & .207 \\
\hline lettura & 3 & 1 & .092 & .076 & .025 & .010 & .204 \\
\hline risanamento & 4 & 4 & .059 & .126 & .0 & .0 & .185 \\
\hline produzione & 3 & 2 & .053 & .051 & .055 & .016 & .177 \\
\hline regolamento & 3 & 2 & .054 & .006 & .088 & .013 & .163 \\
\hline riciclaggio & 1 & 1 & .105 & .052 & .0 & .0 & .158 \\
\hline sabotaggio & 3 & 3 & .057 & .057 & .0 & .0 & .115 \\
\hline
\end{tabular}


Through syntagmatic co-occurrences, it is possible to find out common nouns occasionally coerced to an event reading. As stated in Pustejovsky (1995), typecoercion is a directional phenomenon. Although additional research is needed, it is the syntactic head which preserves its type in composition and determines the typing of the other element(s). If we consider the syntagmic cues previously reported ("continuare", "cominciare", "precedente", "successivo") and we look at nouns that rarely co-occur with them, we find coercions as occasional usages of non-eventive nouns like for the noun "bombe" [bombs] and "fumo" [smoke] in example (11) and for the noun "impegni" [commitments] in (12):

(11) Rimanemmo quieti senza parlare, con raffiche di mitraglietta, ma a quel punto cominciarono le bombe, così forti che parte dell'edificio cadeva, e cominciò il fumo.

[We stood quietly without talking, with bursts of machine gun, but then the bombs began, so strong that part of building fell, and the smoke began.]

(12) Come è pensabile chiudere il contratto con un governo fortemente indebolito che assumerebbe impegni che poi dovrebbero essere realizzati da un esecutivo successivo.

[How is it thinkable to terminate the contract with a government weakened to make commitments which should then be made by a new government the following year.]

The notion of coercion has been widely investigated in linguistics (de Swart 1998, Michaelis 2004, among others) and, in general terms, can be described as a semantic-type shifting, that is an implicit contextual reinterpretation necessary to resolve semantic conflicts.

Verbs are not the only items which can cause the coercion of noun types; adjectives have a role as well, even if in the GL model adjectives show less coercive power (Pustejovsky \& Bouillon 2004).

However, looking at real data, coercions caused by adjectives seem to be equally plausible with respect to coercions caused by verbs. For example, "frequent" is an adjective used as a diagnostic criterion for event-denoting nouns. As Meinschaefer (2005) notes, there are nouns not morphologically derived by verbs which are compatible with "frequent" (example (13)). 
(13) (a) Jane's frequent illness lead to her dismissal.

(b) Video technology has made this a frequent topic of male sporting conversation. (BNC)

(c) Frequent trains run from London Victoria and Charing Cross. (BNC)

Frequency adjectives, such as "frequent", "occasional", and "yearly", can be interpreted in a formal semantics framework (Schäfer 2007) as quantification over realizations of kinds of events. As a consequence, they can highlight coercions from simple common nouns to complex event expressions (through the enrichment of nouns with an event-kind argument) as in (14):

Agent Cooper likes an occasional cup of coffee.

The importance of adjectives in selecting event nouns - the relevance of syntagmatic cues as "frequent", "future", and "sudden" for coercion - is undeniable.

\section{Methodology and Experiments}

In this section, we will illustrate the methodology used in order to develop a set of experiments for the identification of a statistical measure of eventivity for nouns. The main motivation behind the idea of an eventivity measure for nouns is related to the hypothesis that the notion of event is a scalar one (Simone 2008 among others). Such a measure may provide empirical support to this statement.

The methodology is adapted from Rumshimky et al. (2007), Pustejovsky \& Jezek (2008) and Pantel \& Pennacchiotti (2006). For the identification of event triggers, we have not limited our choice to verbs but we have included adjectives as well.

\subsection{Identifying relevant event triggers cues}

The identification of syntagmatic cues that trigger the eventive reading has been conducted by means of an extensive corpus exploration on two sets of data.

The first set of data is composed by the most frequent nouns in the ISST (Italian Syntactic Semantic Treebank, Montemagni et al. 2003). We have used this reference corpus of Italian to extract the most frequent common nouns. Due to its small dimension (only $305 \mathrm{~K}$ tokens), we have set the threshold for "highly frequent" to all common nouns which occur in the corpus with a min- 
imum frequency of 20 occurrences. In order to ease the identification of event nouns, we have connected this set of nouns, which for clarity reasons we will call Nouns_Treebank, to a Generative Lexicon-based Lexical Resource, namely SIMPLE/CLIPS (Ruimy et al. 2003).

In SIMPLE/CLIPS lexical units are structured in terms of a semantic type system and are characterized and interconnected by means of a rich set of semantic features and relations. The type system consists of 157 language- and domainindependent semantic types designed for the multilingual lexical encoding of concrete and abstract entities, events and properties. The Ontology is a multidimensional type system based on both hierarchical and non-hierarchical conceptual relations, which reflects the Generative Lexicon assumption that lexical items are multidimensional entities with different degrees of internal complexity and thus need lexical semantic descriptions able to account for different ranges of meaning components.

By means of a set of queries, we have extracted from the Noun_Treebank set only those nouns which have at least one semantic type belonging to the "event" node in the SIMPLE/CLIPS Ontology. This reduced set of nouns contains both purely eventive nouns and instances of dot types. We will call this list of nouns SIMPLE_nouns.

The identification of the event triggers, or syntagmatic cues, has been accomplished by means of a second corpus exploration and through a deep exploitation of the SIMPLE_nouns list. In this second experiment, we have used a larger corpus of Italian, namely the La Repubblica corpus which is composed by 308 million tokens. The large dimensions of this corpus allows the identification of a relevant and restricted set of event trigger cues on the basis of the co-occurrences with the SIMPLE_nouns list. In particular, we have queried the La Repubblica corpus with four patterns of occurrence, namely:

- noun - VERB;

- VERB - noun;

- ADJECTIVE - noun

- noun - ADJECTIVE

Due to the lack of access to a parsed version of the La Repubblica corpus, the position of the noun in the co-occurrences patterns with verbs try to mimick the syntactic / grammatical position of subject and object. 
After having extracted the four patterns of occurrence for each noun in the SIMPLE_noun list, we have selected only those event trigger cues with a high frequency, namely at least 800 occurrences for verbs and 1,000 occurrences for adjectives. This reduced list of patterns of occurrence has been manually inspected in order to identify which semantic type of the nouns in the SIMPLE_nouns list was selected. Only those verbs and adjectives which selected the event reading of the nouns were retained and considered good syntagmatic cues for eventivity. In this way, we have selected 76 syntagmatic cues: 37 verbs and 39 adjectives. In Table 6 below we report a sample of the selected cues:

Table 6: Verbal and Adjectival syntagmatic cues.

\begin{tabular}{|l|l|l|}
\hline $\begin{array}{l}\text { Verbs for nouns in } \\
\text { subject position }\end{array}$ & $\begin{array}{l}\text { Verbs for nouns in } \\
\text { object position }\end{array}$ & $\begin{array}{l}\text { Pre- and postmodifier } \\
\text { adjectives }\end{array}$ \\
\hline avvenire & annullare & anticipato \\
continuare & auspicare & attuale \\
restare & cessare & imprevisto \\
risultare & evitare & odierno \\
& ostacolare & successivo \\
\hline
\end{tabular}

The exploration of the extracted data from the La Repubblica corpus has led to the identification of a further set of cues, namely three verbs which frequently co-occur in light verb constructions in Italian, i. e. "mettere" [to put], "fare" [to do] and "dare" [to give]. Though in these cases it is the whole construction (verb + noun in object position) which acquires an eventive reading, we choose to include these verbs both because the nouns co-occurring with them are assumed to have an eventive reading.

\subsection{Normalized frequencies of nouns}

The development of the eventivity measure relies on the idea that specific syntagmatic cues, if relevant, may determine the perception of the degree of eventivity for nouns. Under this perspective, the eventivity measure corresponds to the normalized frequency of a noun in a reference corpus, that the sum of the co-occurrence frequencies of the noun with the syntagmatic cues divided by its absolute frequency, according to the formula in (15):

$$
\frac{\text { frequency noun_cue } 1+\text { frequency noun_cue } 2+\ldots+\text { frequency noun_cue76 }}{\text { absolute frequency noun }}
$$


To test the validity of this hypothesis and the relevance of the selected cues we choose a subset of 200 nouns from the ISST (ISST_test). The nouns which form the ISST_test list have been selected by taking into account two parameters:

- the opposition between morphologically marked (e. g. "costruzione" [building], "occuppazione" [occupation], "pestaggio" [beating],) and "frenata" [braking]) and morphologically unmarked nominalizations (e. g. "accusa" [prosecution], "disegno" [drawing], "corsa” [run]) from corresponding verbs ; and

- non-derived nouns (e.g. "guerra" [war], "assemblea" [meeting], "barone" [baron]).

For the first set of nouns, we have taken into account the productivity of the morphological suffix as reported in Gaeta (2004), in order to balance our data set. The two groups are well balanced since we have 100 nouns for derived forms and 100 nouns for not derived ones.

For each noun in the ISST_test list, we have extracted from the La Repubblica corpus the frequencies of each noun with the set of syntagmatic cues, and have computed its normalized frequency on the basis of the formula described in (15) A sample of the results is reported in Table 7 below:

Table 7: A sample of the results from the first experiment.

\begin{tabular}{|l|l|}
\hline Noun & Event measure \\
\hline assemblea & .040 \\
\hline aumento & .032 \\
\hline relazione & .015 \\
\hline aborto & .010 \\
\hline partecipazione & .007 \\
\hline telegiornale & .004 \\
\hline biotecnologia & .001 \\
\hline
\end{tabular}

A preliminary analysis of the normalized frequencies shows that the nouns in the ISST_test list cluster into three main groups along a continuum whose poles are represented by eventive nouns and non-eventive nouns. It is interesting to notice that the eventive pole of the continuum does not contain only purely eventive nouns such as "pestaggio" [beating], "sconfitta" [defeat] but also the vast majority of dot types of the kind "EVENT ○ NOT_EVENT" (45 out of 88, 51.13\%) such as "dichiarazione" [declaration], "incremento" [increase]. This element provides sup- 
port to the hypothesis that the types which compose a dot type are not always on the same level, but it can be the case that one type is more salient that the other.

\subsection{Lexical resources, eventivity ans syntagmatic cues}

A further experiment for the validation of the syntagmatic cues and the eventivity measure is the analysis of the correlation between the normalized frequencies of the nouns in the ISST_test list and two language resources, namely a lexical resource, ItalWordNet (IWN), and the De Mauro-Paravia Dictionary. Such an analysis is also useful to provide a preliminary evaluation of the two language resources in terms of quality and coverage of the lexical items.

In this case, we have considered the degree of eventivity of a noun as the ratio of the sum of the eventive readings of a noun in the two resources by the total number of senses encoded for that noun, as illustrated in the formula (16):

$$
\frac{\text { event readings IWN_noun1 }+ \text { event readings De Mauro_noun1 }}{\text { total number of senses IWN_noun1 }+ \text { total number of senses DeMauro_noun1 }}
$$

The two resources are very different in terms of their internal structure and this has called for the application of different strategies for the identification of the eventive readings. As for IWN, we have extensively exploited the internal hierarchical organization of the lexical resource and its corresponding ontology by looking for each sense of the nouns in the ISST_test list for the "event" node among its hypernyms. On the other hand, in the De Mauro dictionary, we have looked for key phases in the sense definitions such as the "act of $X$ ", or the "process of $X$ " and similar. In Table 8 below we report a sample of the eventivity measures we have obtained in this experiment.

Similarly to that for speakers' judgements, to evaluate the soundness of the eventivity measure obtained by the formula in (16) we have computed the Spearman correlation between the values obtained from the lexical resources and the syntagmatic cue frequencies. The results are positive since we have obtained a $\rho$ value of .516 for IWN and of .607 for the De Mauro. Though these values are statistically significant, they are somehow biased by the nature of the two language resources which contain information with potential errors. In particular, a detailed analysis of the entries showed that some largely used senses of some nouns are not present in IWN, and that some eventive readings in the De Mauro- 
Converging Evidences on the Eventivity of Italian Nouns

Table 8: Average of eventivity from the two language resources (IWN and De Mauro).

\begin{tabular}{|l|l|}
\hline Noun & $\begin{array}{l}\text { Event average from language } \\
\text { resources (IWN \& De Mauro) }\end{array}$ \\
\hline assemblea & .125 \\
\hline aumento & .333 \\
\hline relazione & .625 \\
\hline aborto & .433 \\
\hline partecipazione & .751 \\
\hline telegiornale & .0 \\
\hline biotecnologia & .0 \\
\hline
\end{tabular}

Paravia are quite obsolete and infrequent. For these reasons, we have decided not to include the contribution of the language resources in the development of the eventivity measure, without integrating the formula in (16) with that reported in (15).

\subsection{Speakers' judgments on eventivity and correlation with the normalized frequencies}

The normalized frequencies we have obtained from the corpus data are numbers: they are not very informative about the validity of the eventivity measure. The only reliable result is represented by the evidence that eventive nouns are more frequent with event triggers cues and non eventive ones are less frequent. Nevertheless, the most interesting results can be derived from the analysis of the "grey zone" of the continuum, that is the large cluster of nouns in the middle between the eventive and non eventive poles.

Since we support the idea that theoretical semantic concepts should be cognitively plausible (Pustejovsky 1995), we compare the results of the corpus analysis with speakers' judgements. When the focus is on semantic categorizations, human judgments are widely acknowledged as a useful source to establish a gold standard or, more generally, they represent the best benchmark, especially when the representation is fuzzy. In computational linguistics, human judgments are used for the evaluation of automatic approaches to linguistic tasks but they also help theoretical linguistics because they provide insights complementary to introspective analysis or evidences gathered from corpora.

Following Hoey's (2005) theoretical characterization of the psycholinguistic notion of priming, according to which every word is mentally primed for col- 
locational use and our knowledge of it includes its co-occurrences features, the comparison between the speakers' representations and corpus information is essential to understand the regularity of the lexical structure. In particular, under this perspective a lexical item is primed for eventivity when its frequencies of co-occurrences with specific triggers are statistically relevant.

Even if the cognitive status of frequency is undeniable for linguistic phenomena, there is a lively debate on the correlation between salience and frequencies in corpora because mappings between structural properties of the mental lexicon and corpus descriptive operationalitions in terms of semantic associations measures could not be straightforward (Lindsey et al. 2007).

To test the validity of the syntagmatic cues, we have performed an experiment with 7 Italian subjects, all of them BA students in Linguistics, in order to compare the speakers' judgements and the corpus observations.

The subjects were asked to classify each noun in the ISST_test list on an eventivity scale ranging from 1 to 5 , where 1 states that the noun has no eventive reading, 5 states that the noun has only the eventive reading, while the other numbers in the scale correspond to mixed readings. The subjects did not receive a special training for this task, but they were provided with a brief description of the task and some examples. It is important to point out the fact that the definition of event which was provided corresponds to the most intuitive definition, i. e. "the noun describes or denotes something which happen or occur in the world". In Table 9 below, we report the average measures of eventivity provided by the speakers:

Table 9: Average of the speakers' judgments on eventivity

\begin{tabular}{|l|l|}
\hline Noun & $\begin{array}{l}\text { Event average from speakers' } \\
\text { judgements }\end{array}$ \\
\hline assemblea & 2,86 \\
\hline aumento & 3,86 \\
\hline relazione & 2,86 \\
\hline aborto & 5 \\
\hline partecipazione & 3,86 \\
\hline telegiornale & 1,71 \\
\hline biotecnologia & 1 \\
\hline
\end{tabular}

In order to identify a statistical threshold of eventivity, we have computed the correlation between the speakers' judgments and the normalized frequencies by 
means of the Spearman coefficient. The results of the correlation are very encouraging since we have a highly convergent $\rho$ value $(\rho=.731)$. This value, on the one hand, supports the validity of the syntagmatic cues we have identified and, on the other hand, it provides further support to the proposal of the notion of eventivity as a scalar concept in the noun domain. In addition to this, it is interesting to notice that the speakers' judgments correlate more with the syntagmatic cues for non morphologically derived nouns than with the morphologically marked ones.

\section{A practical application: event annotation by means of the eventity measure}

On the basis of the analyses described in the previous sections, and in particular on the basis of the high correlation between the normalized frequencies between the syntagmatic cues and speakers' judgments, we have decided to consider as a good threshold for eventivity a measure of the normalized frequencies equals or higher than 0.01 (it corresponds to the 4th quartile of the frequency distribution). We thus propose to use this measure as a statistical parameter to support the annotation of event nouns in corpora.

In order to evaluate our proposal, we have performed an annotation experiment on an Italian corpus. The corpus is composed by 149 newspaper articles, for a total of more than 63 thousand tokens, with 18,308 of them being labelled as nouns. Six human annotators have manually applied TimeML specifications (Pustejovsky et al. 2003) by distinguishing between temporal expressions, events and signals. 4,369 noun tokens have been tagged as event. The overall annotation accuracy is $77 \%$, a level which guarantees a good reliability. The set of nouns in the annotated corpus will represent the gold standard against which we will evaluate the validity of the eventivity measure. Before applying the eventivity measure, we have lemmatized the nouns and cleaned this list by means of two stop-word lists which have been created from SIMPLE/CLIPS. The first is a list of items which are always eventive. This list contains words such as "causa" [cause], "occasione" [occasion] and all the nouns belonging to type "phenomenon" which is a subtype of the "event" type, but excluding nouns like "calore" [heat] which are phenomena but may assume an eventive reading only in special contexts. The second list, on the contrary, is a list of words which are never events. This second 
list has been obtained by extracting all the nouns which belong to the types "time" and "amount".

After this operation the following data are available to be analyzed by means of the eventivity measure: (i) 811 lemmas which have never been annotated as eventive (non-eventive nouns); (ii) 485 lemmas which have been annotated as eventive and on which annotators agree (eventive nouns); (iii) 78 lemmas on which annotators disagree (disagreement). Once again, the measure has been computed by means of queries from the corpus La Repubblica. Each lemma in the three groups - non eventive nouns, eventive nouns and disagreement - has been automatically annotated either as eventive or as non-eventive on the basis of the threshold. The results are illustrated in Table 10.

Table 10: Percentages of eventive items retrieved by applying the eventivity measure to the three groups of nouns.

\begin{tabular}{|l|l|}
\hline Noun subgroup & Eventive items \\
\hline non-eventive & $105(13 \%)$ \\
\hline eventive & $288(60 \%)$ \\
\hline disagreement & $22(29 \%)$ \\
\hline
\end{tabular}

The figures are impressive since following the measure more that $60 \%$ of the lemmas which had been annotated as event by humans have been identified. This suggests that the eventive measure could be used either as a feature for automatic annotation of event nouns or to support the development of manual datasets for event nouns. Moreover, the very low number of false positives - i.e non-eventive noun types which are above the threshold - is encouraging since it supports the validity and consistency of the syntagmatic cues we have identified. Finally, the non-eventive nouns which are above the threshold can be considered as good candidates for identifying instances of qualia exploitation and coercion phenomena. As for the disagreement group, the eventivity measure suggests that some items could have an eventive reading, thus providing a statistical index for identifying challenging cases which require a more fine-grained analysis. 


\section{References}

\section{Conclusion and Future Work}

The main contribution of this paper is the identification of a measure for the eventivity of nouns based on syntagmatic cues that is promising from a theoretical point of view (i. e. Generative Lexicon) and useful for practical applications.

In a lexical semantic theory the inclusion of a lexical item in wide semantic classes such as the event nouns class should be based on language usages. The continuum that emerges by the corpus based analyses proposed in this work indicates that the membership is a matter of degree.

From a practical point of view, the eventivity measure can be used as a statistical measure to automatically annotate event nouns in corpora. Moreover, the measure can be used as a strategy to implement robust annotation systems which integrate information from large lexical resources, like SIMPLE/CLIPS and IWN. A further advantage of the measure is the fact that it could be used to discover probable instances of dot types or coerced events. This can be achieved by lowering the threshold. For instance, nouns with an eventivity measure very near to the threshold, e. g. 0.008, could be good candidates.

It is interesting to point out that the eventivity measure can be used also to weight noun types. For instance, it could be the case that some dot types objects are perfectly balanced between the two types, but it could also be the contrary, that is, several dot type objects could be assembled with components that vary for their salience. Evidence to this hypothesis could be found among the disagreement nouns which are above the threshold.

\section{References}

Baroni, M., Bernardini S., Comastri F., Piccioni L., Volpi A., Aston G., \& Mazzoleni M. 2004. Introducing the "la Repubblica" corpus: A large, annotated, TEI(XML)-compliant corpus of newspaper italian. Proceedings of the Fourth International conference on Language Resources and Evaluation (LREC-04).

Baroni, M. \& A. Lenci. 2010. Distributional Memory: A general framework for corpus-based semantics, Computational Linguistics, 36 (4). 1-49.

Basili, R., \& M. Pennacchiotti. 2010. Distributional Lexical Semantics: Toward uniform representation paradigms for advanced acquisition and processing tasks. Natural Language Engeneeringing 16 (4). 347-358. 
Bertuccelli Papi, M., M. Cappelli, \& S. Masi (eds.). 2007. Lexical complexity: theoretical assessment and translational perspectives. Pisa: Plus Pisa University Press.

Boleda, G., T. Badia, \& E. Batlle. 2004. Acquisition of semantic classes for adjectives from distributional evidence. Proceedings of Coling 2004, 1119-1125.

De Mauro, T. 2004. Il Dizionario di Italiano Paravia. Paravia, Milano.

de Swart, H. 1998. Aspect shift and coercion. Natural Language and Linguistic Theory 16 (2). 347-385.

Lin, D. 1998. Automatic retrieval and clustering of similar words. Proceedings of the 36th Annual Meeting of the Association for Computational Linguistics, 768774.

Gaeta, L. 2004. Nomi d' azione. In M. Grossmann \& Rainer F., (eds.), La formazione delle parole in italiano, 314-351. Tübingen: Niemeyer.

Grimshaw, J. 1990. Argument Structure. Cambridge: MIT Press.

Gross, G. \& F. Kiefer. 1995. La structure événementielle des substantifs. Folia Linguistica 29 (1-2). 45-65.

Hoey, M. 2005. Lexical Priming: A new theory of words and language. London: Routledge.

Hovy E. 2010. Distributional Semantics and the Lexicon. Proceedings of the 2nd Workshop on Cognitive Aspects of the Lexicon (CogALex 2010).

Lindsey, R., V.D. Veksler, A. Grintsvayg, \& W. D. Gray. 2007. Be Wary of What Your Computer Reads: The Effects of Corpus Selection on Measuring Semantic Relatedness. Proceedings of the 8th International Conference on Cognitive Modeling.

Lenci, A. 2008. Distributional semantics in linguistic and cognitive research, in A. Lenci (ed.), From context to meaning: distributional models of the lexicon in linguistics and cognitive science, Italian Journal of Linguistics 20 (1). 1-31.

McDonald, M. A. \& R. C. Schillcock. 2001. Rethinking the word frequency effect: the neglected role of distributional information in lexical processing. Language and Speech 44 (3). 295-323.

Meinschaefer, J. 2005. Event-oriented adjectives and the semantics of deverbal nouns in germanic and romance: The role of boundedness and the mass/count distinction. In A. M. Thornton \& M. Grossmann (eds.), La formazione delle parole in italiano, 355-368. Roma: Bulzoni. 


\section{References}

Montemagni, S., F. Barsotti, M. Battista, N. Calzolari, O. Corazzar, A. Lenci, V. Pirelli, A. Zampolli, F. Fanciulli, M. Massetani, R. Raffaelli, R. Basili, M. T. Pazienza, D. Saracino, F. Zanzotto, N. Mana, F. Pianesi, \& R. Delmonte. 2003. The syntactic-semantic treebank of Italian. An overview. Special Issue: Linguistica Computazionale, Computational Linguistics in Pisa, XVIII-XIX, 461493.

Pantel, P. \& M. Pennacchiotti. 2006. Espresso: Leveraging generic patterns for automatically harvesting semantic relations. Proceedings of the 21st International Conference on Computational Linguistics and 44th Annual Meeting of the Association for Computational Linguistics, 113-120.

Pustejovsky, J. \& P. Bouillon. 2004. On the proper role of coercion in semantic typing. Proceedings of the 15th International Conference on Computational Linguistics (COLING-94), 706-711.

Pustejovsky, J. \& E. Jezeck. 2008. Semantic coercion in language: Beyond distributional analysis. Italian Journal of Linguistics - Special Issue: Distributional Models of the Lexicon in Linguistics and Cognitive Science, 20(1).

Pustejovsky, J., J. Castao, R. Ingria, R. Saur'1, R. Gaizauskas, A. Setzer, \& G. Katz. 2003. TimeML: Robust specification of event and temporal expressions in text. Fifth International Workshop on Computational Semantics (IWCS-5).

Pustejovsky. J. 1995. The Generative Lexicon. Cambridge: MIT Press.

Ruimy, N. M. Monachini, E. Gola, N. Calzolari, M.C. Del Fiorentino, M. Ulivieri, \& S. Rossi. 2003. A computational semantic lexicon of Italian: SIMPLE. Special Issue: Linguistica Computazionale, Computational Linguistics in Pisa, XVIIIXIX, 821-864.

Rumshimsky, A., V. Grinberg, \& J. Pustejovsky. 2007. Detecting selectional behaviour of complex types in text. Proceedings of the 4th International Workshop on Generative Approaches to the Lexicon.

Schäfer, R. 2007. On frequency adjectives. In E. Puig-Waldmüller (ed.), Proceedings of Sinn und Bedeutung 11, 555-567.

Simone, R. 2008. Coefficienti verbali nei nomi. In P.M. Bertinetto (ed.), Il verbo. Atti del Congresso annuale della SIG - Società Italiana di Glottologia.

Vendler, Z. 1967. Linguistics in Philosophy. Ithaca: Cornell University Press.

Zucchi, A. 1993. The Language of Propositions and Events. Dordrecht: Kluwer Academic Publishers. 


\section{Authors}

Irene Russo

Istituto di Linguistica Computazionale

CNR

irene.russo@ilc.cnr.it

Tommaso Caselli

Trento RISE

t.caselli@gmail.com 